\title{
O Papel das Políticas de Fomento ao Setor Audiovisual e a Construção da Imagem da Cidade de São Paulo: o caso da Spcine
}

The role of policies to promote the audiovisual sector and the construction of the image of the city of São Paulo: the case of Spcine

Raphael Brito Faustino - Faculdade Cásper Líbero | São Paulo | SP | Brasil | E-mail: rbfaustino@casperlibero.edu.br | https://orcid.org/0000-0002-1706-8082

Resumo: O presente trabalho tem como objetivo avaliar as políticas de fomento ao setor audiovisual, em especial a atuação da Empresa de Cinema e Audiovisual de São Paulo (Spcine). Utilizando-se do referencial teórico da Economia Política da Comunicação e da Economia Criativa, identifica-se que a proposta da Spcine busca fomentar o setor audiovisual na cidade de São Paulo, em especial a partir dos seus impactos econômicos e na promoção da cidade no circuito das cidades globais. Para tal, destaca-se brevemente a estruturação da política de fomento ao setor audiovisual desenvolvida no Brasil nas últimas décadas, bem como a atuação da Spcine, evidenciando assim, seus principais programas e os recursos aplicados. Neste sentido, avalia-se criticamente o papel da cultura como agente no processo de formação da imagem e marketing urbano.

Palavras-chave: Economia criativa. Leis de fomento ao audiovisual. Política Pública. Audiovisual. Spcine. Cidades globais.

Abstract: This paper aims to evaluate the promotion policies for the audiovisual sector, especially the performance of the São Paulo Film and Audiovisual Company (Spcine). This discussion will use the theoretical framework of Political Economy of Communication and Creative Economy. The paper identifies that the proposal of Spcine seeks to promote the audiovisual sector in the city of São Paulo, especially from its economic impacts and the promotion of the city in the circuit of global cities. To this end, we highlight briefly the structuring of the policy to promote the audiovisual sector developed in Brazil in recent decades, as well as the performance of Spcine, highlighting its main programs and the resources applied. In this sense, the role of culture as an agent in the process of image formation and urban marketing is critically evaluated.

Keywords: Creative economy. Audiovisual laws. Audiovisual policy. Spcine. Global cities.

- Recebido em: 04 nov. 2019 - Aprovado em: 08 dez. 2019 - e-ISSN: 2177-5788

DOI: https://doi.org/10.22484/2177-5788.2019v45n2p307-330

Copyright @ 2019. Conteúdo de acesso aberto, distribuído sob os termos da Licença Internacional da CreativeCommons - CC BY-NC-SA - Atribuição Não Comercial (https://br.creativecommons.org/licencas/) - Permite distribuição e reprodução, desde que atribuam os devido créditos à publicação, ao autor(es) e que licenciem as novas criações sob termos idênticos. 


\title{
1 Introdução
}

A Economia Política da Comunicação pode ser considerada uma área dos estudos sobre comunicação com importante avanço teórico, segundo Ferreira, Morais e Jambeiro (2017), em especial na construção de interpretações sobre a relação do Estado com o mercado, a sociedade e a mídia.

\begin{abstract}
A essência da Economia Política da Comunicação está no postulado de que a conjunção de fatores econômicos e políticos são centrais para a compreensão do que ocorre no setor e para a formulação de políticas públicas voltadas para os serviços de informação e comunicação (FERREIRA; MORAIS; JAMBEIRO, 2017, p. 7).
\end{abstract}

Ainda segundo os autores, inserido neste marco teórico, o setor audiovisual apresenta-se como relevante recorte, principalmente através de análises relacionadas à produção de conteúdo, participação do Estado e dos mercados nas estruturas da indústria audiovisual.

Morais (2016) sugere o desenvolvimento de uma breve análise sobre a Economia Política do Audiovisual, identificando suas instituições, atores e ideias, de forma a compreender as especificidades do setor, bem como analisar parte das políticas públicas desenvolvidas nos últimos anos. A autora ainda destaca que as reflexões realizadas sobre a produção audiovisual, normalmente são compostas por análises fílmicas e estéticas dos produtos, além de estudos de cunho sociológico e filosófico. Contudo, afirma:

Ocorre que, para que o conteúdo audiovisual possa ser criado, há toda uma infraestrutura (econômica, jurídica, cultural etc.) que o suporta. Trata-se de um fenômeno que teve origem na Revolução Industrial e se desenvolveu com o processo de industrialização, subordinado, portanto, à dinâmica capitalista (MORAIS, 2016, p. 39).

REU, Sorocaba, SP, v. 45, n. 2, p. 307-330, dez. 2019. 
Faz-se necessário, então, compreender como um setor que mistura a lógica industrial de produção, associada à arte e criatividade, desenvolve a estrutura material necessária para concorrer em um mercado extremamente competitivo. Morais (2016) destaca que as políticas protecionistas e de fomento tem sido as opções adotadas por uma série de países, principalmente os países em desenvolvimento, como o Brasil.

Como referencial teórico para esta interpretação, a Economia Política da Comunicação destaca-se com importante contribuição, inclusive com esforços para analisar criticamente a ação do Estado no fomento à produção audiovisual. Neste sentido, Santos (2017) utiliza o referencial desenvolvido pela Economia Política da Comunicação para interpretar a política do audiovisual.

Dessa forma, a relevância da política pública do audiovisual insere-se em um contexto amplo de análise, destacando-se não apenas pela importância econômica do setor na economia brasileira e sua participação no orçamento público, segundo Morais (2016), mas também pelo seu impacto sobre a população, o diálogo com outros setores, como a cultura, a comunicação social e as telecomunicações, além da sua interface e impactos nos locais em que a política passa a ser efetivamente implementada.

Cabe destacar que as interações relacionadas à política pública superam a simples intervenção do Estado em determinada situação social. Como define Giovanni (2009), a política pública pode ser definida como um exercício de poder nas sociedades democráticas, resultando em uma interação ampla entre Estado e sociedade. O autor ainda considera que é justamente através destas interações que se definem as situações sociais que passam por intervenções, bem como as formas, os conteúdos, os meios, os sentidos e as modalidades de intervenção estatal.

Uma das principais características da história da produção audiovisual no Brasil é seu caráter descontinuado ou cíclico. Em diversos momentos, o setor audiovisual passou por "surtos" de produção, seguidos de momentos REU, Sorocaba, SP, v. 45, n. 2, p. 307-330, dez. 2019. 
de expressiva depressão, para novos "recomeços". Analisando estes períodos, Morais (2016) aponta que o caso brasileiro comprova que, na ausência de participação do Estado na promoção da atividade audiovisual, o setor privado nacional não foi capaz de criar condições para o crescimento sustentado do setor.

Neste contexto, a política pública do audiovisual, desenvolvida a partir dos anos 1990, parece estabelecer um novo momento na atuação do Estado no setor. Ao longo do período, desenvolve-se uma estrutura institucional, programas e fontes de financiamento, que visam promover um ciclo contínuo de crescimento e desenvolvimento das atividades, na tentativa de superar o padrão histórico visto até então.

As políticas de fomento ao setor audiovisual promoveram expressivo incremento na atividade do setor, em especial a partir de meados da década de 2000. Este avanço setorial pode ser considerado indutor de novas formas de atuação do Estado, como o desenvolvimento de estratégias locais de promoção à atividade audiovisual. Dentre as propostas que se destacam neste sentido podemos inserir a criação da Empresa de Cinema e Audiovisual de São Paulo - Spcine (PREFEITURA..., 2016).

A Spcine foi criada com o intuito de promover o fomento ao setor audiovisual em múltiplos sentidos, como veremos adiante. Destaca-se, contudo, a estratégia de promover a cidade de São Paulo como referência de produção audiovisual na América Latina e promovê-la enquanto cidade global, utilizando-se dos atributos culturais da indústria audiovisual e de suas relações com as dinâmicas globais. Faz-se necessário, portanto, compreender os processos e articulações da política de fomento ao setor audiovisual e, também, suas relações com outras dinâmicas contemporâneas, como o desenvolvimento e o marketing urbano.

Desta forma, o presente trabalho busca interpretar a criação da Spcine e sua perspectiva de promoção da cidade de São Paulo dentro do grupo de cidades globais. Para tal, está estruturado em três seções, além desta introdução e das considerações finais. A primeira seção pretende REU, Sorocaba, SP, v. 45, n. 2, p. 307-330, dez. 2019. 
contextualizar as políticas de fomento ao setor audiovisual, destacando sua estruturação enquanto política pública e na promoção da atividade, do ponto de vista econômico e cultural. A segunda seção analisa a Empresa de Cinema e Audiovisual de São Paulo (Spcine), de forma a compreender a ação local de fomento à atividade audiovisual, bem como seu papel na promoção da cidade como lócus de produção cultural. Por fim, a terceira seção busca interpretar a ações desenvolvidas pela Spcine em um contexto de posicionar a cidade de São Paulo, através do destaque promovido pelo setor audiovisual, no grupo de cidades globais.

\section{Breves Apontamentos Sobre a Política de Fomento ao Audiovisual no Brasil}

O setor audiovisual insere-se, do ponto de vista econômico, em um grupo mais amplo de atividades reunidas no conjunto denominado de Economia Criativa. Ainda que o conceito de economia criativa se apresente de maneira diversa na literatura pertinente ao tema, opta-se para este trabalho pela definição presente em texto do Ministério da Cultura - MINC (2011, p. 23):

partindo das dinâmicas culturais, sociais e econômicas construídas
a partir do ciclo de criação, produção,
distribuição/circulação/difusão e consumo/fruição de bens e
serviços oriundos dos setores criativos, caracterizados pela
prevalência de sua dimensão simbólica.

Para o MINC (2011), o grupo da economia criativa é definido na economia brasileira em seis macrocategorias: patrimônio natural e cultural, espetáculos e celebrações, artes visuais e artesanato, livros e periódicos, audiovisual e mídias interativas e design e serviços criativos. As atividades associadas, que compõem o setor audiovisual e mídias interativas são: cinema e vídeos, TV e rádio (incluindo internet), internet podcasting e vídeo games (incluindo online).

Oliveira, Araújo e Silva (2013) destacam a importância da economia criativa como forma de promover a geração de emprego e renda, a partir 
da diversificação econômica, de receitas, comércio e inovação, em especial quando se analisa a relação simbiótica entre as atividades do setor e as novas tecnologias de informação e comunicação. Ainda segundo os autores, deve-se destacar a importância dos empregos gerados nos setores da economia criativa, uma vez que tendem a pagar melhores salários e são associados a empregos de melhor qualidade.

Ainda segundo os mesmos autores, a partir do documento da United Nations Conference on Trade and Development - UNCTAD (2010), o reconhecimento da importância dos estudos e análises dos setores da economia criativa surge a partir de quatro perspectivas, a saber: a) a conciliação de objetivos nacionais culturais, com as políticas comerciais, tecnológicas e internacionais. b) compreender as assimetrias que impedem o crescimento das indústrias criativas, principalmente em países em desenvolvimento; c) reforçar o "nexo criativo" entre investimento, tecnologia, empreendedorismo e comércio; e d) promover políticas inovadoras para estimular a economia criativa visando desenvolvimento econômico.

Contudo, faz-se necessário uma compreensão crítica a respeito das relações entre os setores criativos e culturais e suas formas de produção e avaliação a partir das perspectivas sugeridas pela economia criativa. A produção cultural, analisada no presente trabalho a partir do setor audiovisual, passa por intenso processo de associação com as ações e dinâmicas do desenvolvimento econômico. Neste sentido, as abordagens propostas pelas bases da economia criativa sugerem a necessidade de avaliação da produção cultural a partir de uma racionalidade econômica que não estaria presente em todas as produções.

A partir da criação de políticas públicas de fomento ao setor audiovisual, na forma como desenvolvidas no Brasil, suas avaliações ocorrem, na maioria dos casos, a partir dos retornos econômicos gerados por estas produções, além de retornos indiretos, como o destaque e a 
valorização de determinadas regiões, promoção e visibilidade de determinadas cidades, impactos positivos no turismo, dentre outros fatores.

Este processo foi apontado por Debord (2008) ao destacar o papel da cultura como motor do desenvolvimento econômico a partir da segunda metade do século XX. O autor ainda salienta os impactos deste processo, do ponto de vista de uma produção cultural voltada ao espetáculo e seus impactos urbanos.

Cabe ressaltar, então, a estrutura de políticas públicas desenvolvidas para o setor audiovisual no Brasil. Neste sentido, o marco regulatório, ações e programas desenvolvidos, bem como as fontes de financiamento para o setor, guardam importante relação com a promoção da cultura enquanto fonte de desenvolvimento econômico e geração de renda, incluindo seus impactos econômicos locais.

Em resumo, segundo Morais (2016), a política de fomento audiovisual no Brasil divide-se em três mecanismos, a saber: o fomento indireto, através de incentivos fiscais, como a Lei do Audiovisual e a Lei Rouanet; o fomento direto e o Fundo Setorial do Audiovisual (FSA). Atualmente, o FSA destaca-se como principal mecanismo de atuação do Estado brasileiro no fomento à produção audiovisual.

Conforme descrito por Tendências Consultoria Integrada (2016), a partir da década de 1990, estrutura-se importante marco regulatório para o setor audiovisual, com impactos decisivos na retomada da produção audiovisual brasileira e fortalecimento do setor. A criação das leis de incentivo, como a Lei Rouanet (1991) e Lei do Audiovisual (1993), marcam a retomada do setor audiovisual no Brasil, com elevação dos recursos disponíveis e, ainda hoje, cumprem papel importante no financiamento de suas atividades.

Já no ano de 2001, destaca-se a criação da Agência Nacional do Cinema (ANCINE) e, também, a instituição da Contribuição para o Desenvolvimento da Indústria Cinematográfica Nacional (CONDECINE). A 
ANCINE foi criada com o objetivo de fomentar, regular e fiscalizar o mercado de cinema no Brasil. Desde então, sua atuação foi ampliada e atualmente, como define Morais (2016), cumpre papel central na política de fomento ao setor audiovisual, acumulando as funções de regulador e fomentador, com sua regulação restrita ao mercado cinematográfico e suas ações de fomento, que visam o mercado de produção para diversos segmentos, como cinema, TV, games, etc.

A CONDECINE busca manter uma fonte de financiamento estável para o setor audiovisual, com a tributação incidente sobre a exibição e aluguel de filmes, sobre as operações de TV aberta e TV por assinatura, incluindo as empresas de telecomunicações que operam neste último. Os recursos originários da tributação destas atividades são alocados para incentivo a novas produções, a partir do Fundo Setorial do Audiovisual (FSA).

O Fundo Setorial do Audiovisual (FSA) foi desenvolvido para promover uma política de maior envergadura no setor, uma vez que busca atuar também em outros elos da cadeia produtiva do audiovisual, como a distribuição e a exibição. Sua inovação decorre da garantia de recursos perenes, uma vez que estão garantidos através da vinculação de receitas cobradas do próprio setor, através da CONDECINE.

Como destaca Morais (2016), o FSA busca a articulação de todos os elos da cadeia produtiva do audiovisual, englobando linhas de financiamento para o cinema, TV e infraestrutura de serviço. A autora ressalta que a estrutura de financiamento do Fundo distingue-se do fomento indireto, ao retirar do mercado as decisões de financiamento, algo de fundamental importância na estruturação de uma política de acesso aos recursos, de fato, democrática.

O FSA também destacou especial atenção para a produção independente, garantindo a participação destes como importantes atores no desenvolvimento de conteúdo nacional, associando-se com distribuidoras, canais de TV e programadoras. Esta estrutura promove nova orientação da produção audiovisual no Brasil, tanto para o setor de cinema, REU, Sorocaba, SP, v. 45, n. 2, p. 307-330, dez. 2019. 
quanto para a produção em outras áreas, como TV, e foi fundamental na promoção da chamada Lei da TV Paga (2011).

A Lei da TV Paga apresenta especial destaque por promover a produção de conteúdo nacional e sua exibição nos canais de TV por assinatura. A Lei introduziu uma cota de produto nacional, de 3h30 semanais, a ser exibida em horário nobre, nos canais qualificados, com metade dessa produção necessariamente produzida por produtora brasileira independente. Os impactos da criação de demanda promovida pela Lei foram rapidamente percebidos pelo setor, com importantes investimentos a partir de sua regulamentação.

A Lei da TV Paga também modifica o padrão de financiamento do setor audiovisual ao instituir a cobrança da CONDECINE sobre as atividades das empresas de telefonia que atuam como prestadores do serviço de TV por assinatura. Tal fato gerou impacto substancial nos recursos arrecadados para o Fundo Setorial do Audiovisual e elevou sobremaneira suas possibilidades de atuação.

Por fim, o último programa de destaque na composição da política setorial do audiovisual foi Brasil de Todas as Telas (2014). A partir de um diagnóstico da ANCINE, realizado em seu Plano de Diretrizes e Metas para - Audiovisual, foi estruturado o Programa Brasil de Todas as Telas, atualmente definido como o principal programa na alocação de recursos do FSA.

Este conjunto de ações e programas que compõem o marco regulatório e as políticas públicas voltadas à promoção do setor audiovisual podem ser considerados ponto fundamental do crescimento das atividades relacionados ao setor no período recente. Este processo, conforme dados da Associação Brasileira de Produção de Obras Audiovisuais - APRO (2016), promoveu significativo aumento da produção audiovisual no Brasil.

Contudo, a estabilidade institucional e a disponibilidade orçamentária, destacadas como pilares fundamentais da retomada do setor audiovisual 
brasileiro, sofrem expressiva modificação, a partir de janeiro de 2019. A reforma administrativa promovida pelo novo governo impacta diretamente na estrutura institucional responsável pelo fomento à atividade audiovisual. Dentre as ações promovidas, destacam-se a extinção do Ministério da Cultura e a transferência de suas atividades para uma Secretaria Especial vinculada ao Ministério da Cidadania, além da transferência do Conselho Nacional de Cinema para a Casa Civil da Presidência da República, conforme consta em BRASIL (2019), no Decreto no 9.919, de 18 de julho de 2019.

A transferência do Conselho Nacional de Cinema para um órgão vinculado à Presidência da República foi entendida por diversos representantes do setor, conforme D'Agostino (2019), como uma forma de promover interferência nos projetos selecionados para a transferência de recursos. Esta posição surge a partir de manifestações realizadas pelo Presidente da República Jair Bolsonaro, ao destacar sua posição em relação à seleção de projetos para incentivo. De acordo com o Presidente, "se não puder ter filtro, nós extinguiremos a Ancine. Privatizaremos ou extinguiremos" (MAIA, 2019, s/p).

Os problemas institucionais agravaram-se em março de 2019, com a publicação do Acórdão 721/2019, conforme consta em Tribunal de Contas da União - TCU (BRASIL, 2019), que suspendeu a transferência de recursos pela Ancine para os projetos em andamento, bem como a celebração de novos contratos, uma vez que foram considerados irregulares os procedimentos de prestação de contas dos recursos aplicados.

Ainda neste cenário, cabe ressaltar que a estrutura administrativa da Ancine também passa por problemas. A Agência é composta por uma instância deliberativa composta por quatro diretores, responsáveis pelas principais decisões relacionadas às políticas de fomento. No momento de redação deste trabalho, a Ancine encontra-se com apenas um diretor em atividade, uma vez que o Governo Federal não indicou os demais diretores da Agência. Tal fato impacta sobremaneira as ações da Ancine, já que o 
órgão não pode aprovar uma série de ações sem a composição de sua estrutura administrativa completa, segundo Sousa (2019).

Por fim, os impactos destas modificações podem ser identificados nos projetos em andamento e em novas contratações. De acordo com Kachani (2019), o setor audiovisual já sofre com a suspensão dos recursos repassados pela Ancine, com o fechamento de produtoras e demissão de funcionários. Ainda neste sentido, segundo o Observatório Brasileiro do Cinema e do Audiovisual (OCA/ANCINE) ${ }^{1}$ não foram realizadas novas chamadas para contratação de projetos através do Fundo Setorial do Audiovisual no ano de 2019.

Tal fato tem especial relevância para o setor audiovisual nos próximos anos. A interrupção de seleção e contratação de projetos impacta a produção audiovisual não apenas no ano vigente, mas também, o andamento de projetos ao longo dos próximos anos, uma vez que a defasagem temporal entre a contratação e o desenvolvimento das obras implica que as contratações realizadas em determinado ano se efetivem em produção nos anos subsequentes.

Ainda que o cenário contemporâneo aponte para uma inflexão nas políticas de fomento, o crescimento verificado no período anterior promoveu o desenvolvimento de ações locais vinculadas às políticas federais de promoção do setor audiovisual. Dentre os exemplos de destaque, podemos considerar a criação da Empresa de Cinema e Audiovisual de São Paulo (Spcine).

\section{Arranjos Locais e a Empresa de Cinema e Audiovisual de São Paulo (Spcine)}

A Empresa de Cinema e Audiovisual de São Paulo (Spcine) foi criada tendo como objeto social a promoção do desenvolvimento econômico, social, cultural, artístico, tecnológico e científico da atividade

\footnotetext{
${ }^{1}$ Posição de setembro de 2019.

REU, Sorocaba, SP, v. 45, n. 2, p. 307-330, dez. 2019.
} 
cinematográfica e audiovisual do Município de São Paulo². A Spcine é estruturada, então, de forma a destacar a atividade audiovisual, que passa a contar com uma política pública voltada para sua expansão na cidade de São Paulo, buscando aproveitar o potencial econômico e cultural gerado pelo setor audiovisual.

A Spcine surge de uma parceria entre o Município de São Paulo, Governo Estadual e Governo Federal, através da ANCINE, com o intuito de integrar as diversas políticas de fomento criadas nas variadas esferas de governo, buscando estimular o setor audiovisual na cidade de São Paulo a partir de múltiplas perspectivas. De acordo com Ribeiro (2017), a Spcine foi estruturada de maneira a não se transformar em uma mera agência de fomento, nas palavras do autor:

[...] ao prever já em seu extenso objeto social no artigo $2^{\circ}$, conforme citado anteriormente, não apenas na área cinematográfica, mas em "áreas correlatas", podendo a empresa "explorar serviços de radiodifusão sonora e de sons e imagens, observada a legislação aplicável", a Spcine tenha trabalhado em seus dois primeiros anos de existência, não apenas apoiando prioritariamente a chamada produção independente do cinema paulistano, mas também áreas ascendentes no mercado audiovisual brasileiro como o mercado de games, séries de TV paga e novas mídias (RIBEIRO, 2017, p. 4876).

De acordo com sua estrutura inicial, a Spcine apresenta três eixos de atuação, como consta no Diário Oficial (2016), de forma a estimular a cadeia produtiva do setor audiovisual, a saber: 1) Inovação, Criatividade e Acesso, que busca promover a inserção do cidadão no circuito audiovisual, apoiando estratégias de desenvolvimento criativo e inovação, empreendedorismo e qualificação profissional; 2) Desenvolvimento Econômico, com ações que visam o desenvolvimento do mercado audiovisual, promovendo estudos setoriais e investimentos considerados estratégicos, com o intuito de impulsionar a participação do setor

\footnotetext{
${ }^{2}$ De acordo com a Lei no 15.929, de 20 de dezembro DE 2013, que autoriza a constituição da Empresa de Cinema e Audiovisual de São Paulo.
}

REU, Sorocaba, SP, v. 45, n. 2, p. 307-330, dez. 2019. 
audiovisual na cidade de São Paulo; e 3) Integração e Internacionalização, que busca estimular as coproduções, a atração de produções estrangeiras, a exportação do conteúdo audiovisual paulista, de forma a tornar a cidade uma referência na produção audiovisual.

A Spcine estrutura uma série de programas de fomento ao setor audiovisual, utilizando-se, em parte, da estrutura desenvolvida em âmbito federal a partir da ANCINE, bem como buscando promover sinergias com outros setores econômicos também presentes na cidade de São Paulo. Para compreender as ações desenvolvidas pela empresa, este trabalho solicitou informações sobre os programas desenvolvidos e os recursos aplicados pela Empresa, através da Lei de Acesso à Informação, com dados encaminhados pela Secretaria Municipal de Cultura do Município de São Paulo, em 02 de agosto de $2019^{3}$. Dentre os programas de maior representatividade, destacam-se os editais de fomento ao setor audiovisual, a criação do Circuito Spcine de Salas de Cinema e a atuação da SP Film Comission.

Os editais de fomento desenvolvidos pela Spcine foram estruturados a partir da proposta da empresa em sua lei de criação, estimulando a produção audiovisual, mas também, outras áreas vinculadas ao setor. Destaca-se, entretanto, o fato de os editais de fomento da Spcine reproduzirem a lógica desenvolvida pelos editais de fomento da ANCINE, com elevada participação do apoio à produção cinematográfica como área privilegiada no direcionamento de recursos.

De acordo com as informações disponibilizadas, a Spcine aplicou R\$ 30,4 milhões através de editais de fomento. Deste total de recursos, aproximadamente $\mathrm{R} \$ 20,7$ milhões $(67,97 \%$ do total) foram destinados à produção cinematográfica, na maioria das ações em articulação com o

\footnotetext{
3 As informações apresentadas neste artigo foram obtidas após consulta à Secretaria Municipal de Cultura do Município de São Paulo, através do protocolo 40896, com solicitação dos recursos investidos pela SPCine. Os dados encaminhados apresentam os recursos aplicados no período entre 2015, ano de efetivo início das operações da SPCine, e julho de 2019.
} 
Fundo Setorial do Audiovisual. Em seguida, o apoio à distribuição cinematográfica recebeu $R \$ 4,3$ milhões (14,42\% do total). Destacam-se, ainda, os editais de apoio a produção de roteiros e desenvolvimento de games, que receberam $R \$ 1,6$ milhões e $R \$ 1,9$ milhões, respectivamente.

Já o Circuito Spcine de Salas de Cinema, busca promover a democratização do acesso às salas de cinema, através da ampliação do parque de exibição cinematográfica da cidade, utilizando-se de estrutura já instalada, como centros culturais, CEUs, teatro e bibliotecas. Busca-se, também, promover a exibição cinematográfica em todas as regiões da cidade e a preços acessíveis.

As salas de cinema do Circuito Spcine foram instaladas prioritariamente nos Centros Educacionais Unificados da cidade de São Paulo (CEUs), com o objetivo de descentralizar a exibição cinematográfica na cidade, tradicionalmente localizada nos shopping centers e nas regiões centrais da cidade. Para tal, foram investidos aproximadamente $R \$ 22,6$ milhões, entre 2016 e 2019, na aquisição de equipamentos, operação e programação das exibições. São realizadas, em média, 9.700 sessões ao ano e o público anual, em média, atinge 458 mil espectadores.

Por fim, a SP Film Comission foi criada para promover a cidade de São Paulo como cenário na produção audiovisual e viabilizar filmagens que utilizem os espaços da cidade na produção. Tal proposta estava definida na Lei de criação da Spcine, com o intuito de facilitar as filmagens e promover a imagem da Cidade de São Paulo. A proposta, então, foi de aproveitar-se da grande quantidade de agências publicitárias para promover gravações na cidade, bem como incentivar gravações de obras cinematográficas, séries e programas de televisão, nacionais e internacionais.

De acordo com a Secretaria Municipal de Cultura, no período entre maio de 2016 e junho de 2019, a cidade de São Paulo recebeu, oficialmente, 3.398 filmagens, que representaram uma movimentação econômica superior a $R \$ 1,5$ bilhões, gerando 75.832 postos de trabalho. 
Ainda segundo a Secretaria, a movimentação econômica é avaliada a partir das informações das produções, ao fazerem o cadastro de suas obras para solicitarem autorização de filmagem preenchem a etapa de Pesquisa Socioeconômica. A SP Film Commission garante o sigilo dessas informações, se propondo a não fazer divulgação de forma individual e sim em conjunto, ou seja, a partir da somatória das informações relativas a cada obra audiovisual cadastrada e atendida pelo departamento. Os valores de movimentação econômica se baseiam no custo e orçamentos informados da produção ${ }^{4}$.

Ao longo do período de operação da Spcine, as ações da SP Film Comission ganharam maior destaque em relação aos outros programas e ações desenvolvidas. Como aponta Parente (2019), a cidade se transformou na Meca do Cinema na América Latina, superando outras cidades da região, como importante polo de produção cinematográfica. O autor ressalta que produções internacionais de vulto como Sense 8, Black Mirror e Conquest, séries da empresa de streaming Netflix, tiveram episódios gravados na cidade.

Neste sentido, busca-se, então, compreender como a política de fomento ao setor audiovisual direciona-se para a promoção da imagem da cidade e a construção de imagens e símbolos, de forma a posicioná-la em um grupo de cidades que possuem, dentre outros fatores, a cultura como elemento importante do seu posicionamento e competição global.

\section{A Spcine como agente da construção da imagem da cidade de São Paulo}

Como descrito nas sessões anteriores, nas últimas décadas, o Brasil estruturou uma destacada política de fomento ao setor audiovisual, que se

\footnotetext{
${ }^{4}$ Cabe ressaltar que a divulgação da movimentação econômica, na forma como esclarecida pela Secretaria de Cultura, não implica que este processo ocorra exclusivamente na cidade de São Paulo, uma vez que os custos das produções estão dispersos por diversas localidades.
} 
estabeleceu a partir de ações do Governo Federal e gerou repercussões nas esferas locais, como apresentado a partir dos programas da Spcine.

Este artigo sugere que parte expressiva das avaliações sobre o sucesso das políticas desenvolvidas foram realizadas a partir dos resultados econômicos produzidos pelo setor audiovisual, deixando em segundo plano suas características culturais e simbólicas. Tal fato também está contido nas avaliações sobre ações e resultados da Spcine, em conjunto com a ação de promover a cidade de São Paulo, em múltiplas perspectivas, visando distinguir-se em um contexto de competição entre grandes cidades globais.

As ações desenvolvidas pela Spcine ganharam relativo protagonismo nos últimos anos, em especial pela tentativa de posicionar a cidade de São Paulo como o principal polo produtor audiovisual da América Latina, superando cidades como o Rio de Janeiro, Buenos Aires e Bogotá. Cabe ressaltar que, ainda que este processo garanta um certo retorno econômico, não apresenta, necessariamente, maior diversificação e democratização dos acessos aos bens audiovisuais e culturais.

A perspectiva da economia criativa como motor do desenvolvimento regional avança em escala global nas últimas décadas. O processo de globalização promoveu uma intensa competição entre cidades na busca por fluxos de capitais, que promoveriam investimentos locais e desenvolvimento econômico. Esta interpretação sobre a busca por investimentos nas cidades surge com o conceito de cidade global, desenvolvido pela socióloga Sassen (1988).

Como destaca Ferreira (2003), a competição pelos fluxos de capitais em uma economia globalizada, bem como novos processos de renovação urbana, tem como característica a utilização da cultura como ponto importante deste processo. Dentre os atributos necessários para posicionar uma cidade no seleto grupo de cidades globais, a realização de produtos culturais, incluindo a produção e exposição de produtos audiovisuais, tem ganhado cada vez mais destaque. Arantes (2000), vai destacar a cultura como peça chave de uma dinâmica de espetáculo na promoção das cidades. REU, Sorocaba, SP, v. 45, n. 2, p. 307-330, dez. 2019. 
Ainda segundo Ferreira (2003), este processo não ocorre com vistas a promoção e ao desenvolvimento cultural, mas sim, carregado de conteúdos simbólicos na promoção de cidades:

[...] o evento capaz de promover o ressuscitamento de bairros e cidades para seu novo papel no cenário global tornou-se, na prática, mais importante do que a produção cultural em si, no que parece ser uma espécie de espelhamento para o campo urbanístico daquilo que se tornou o paradigma da economia global: o predomínio absoluto da marca, acima até do produto em si (FERREIRA, 2010, p. 222).

O mesmo ponto é destacado por Arantes (2000), ressaltando as formas e procedimentos do planejamento estratégico urbano para vender um produto como as cidades. Neste processo, a produção cultural, em suas variadas formas ganha destaque. Nas palavras da autora:

[...] a participação ativa das cidades nas redes globais via competitividades econômica, obedecendo portanto a todos os requisitos de uma empresa gerida de acordo com os princípios da eficiência máxima, e prestação de serviços capaz de devolver aos moradores algo como a sensação de cidadania, sabiamente induzida através das atividades culturais que Ihes estimulem a criatividade, Ihes aumentem a autoestima, ou os capacitem do ponto de vista técnico e científico. Tais iniciativas, sejam elas grandes investimentos em equipamentos culturais ou preservação e restauração de algo que é alçado ao status de patrimônio, constituem pois uma dimensão associada à primeira, na condição de isca ou imagem publicitária (ARANTES, 2000, p. 47).

Este processo é identificado a partir da análise de material produzido pela Prefeitura de São Paulo na última década, em que esta perspectiva tornou-se majoritária dentre os formuladores de política pública na cidade. Relevante esforço foi desenvolvido para inserir a cidade de São Paulo no grupo de cidades criativas, no sentido de promover estes setores como forma de desenvolvimento econômico. Como destaca Caio Luiz de Carvalho, então presidente da São Paulo Turismo:

Cidades com vocação para a cultura e eventos e com um celeiro de grandes talentos, inseridas nesse conceito, devem investir nisso de forma cada vez mais planejada e articulada, criando leis e políticas locais que propiciem investimentos majorados para a cultura e os demais setores criativos, gerando mais conhecimento, empregos e 


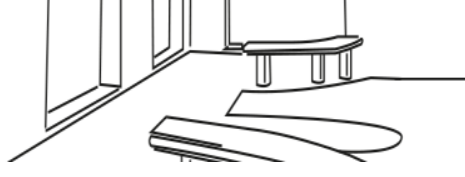

renda e se tornando mais inclusivas, em busca do desenvolvimento sustentável (CARVALHO, 2011, p. 20).

A perspectiva de decadência de um padrão de acumulação baseado na industrialização e a necessidade de substituir o modelo de desenvolvimento vigente, principalmente em cidades com forte participação da indústria em seu processo de desenvolvimento econômico, como é o caso de São Paulo, encontra nos processos vinculados à cultura uma alternativa. Ferreira (2010) destaca que esse processo ocorre de forma a utilizar a cultura como uma política de revitalização socioeconômica e estratégia de marketing urbano.

Esta perspectiva associa-se com as definições da economia criativa, como forma de promover desenvolvimento econômico e geração de renda através dos setores culturais. Machado (2016) aponta que a economia criativa se relaciona com a economia solidária e os arranjos produtivos locais, tornando elementos chave para o desenvolvimento local.

Como destaca Caiado (2011), em estudo organizado pela Secretaria de Governo da Prefeitura de São Paulo, a cidade de São Paulo apresenta uma série de potencialidades para o desenvolvimento de setores econômicos vinculados à economia criativa. A partir da realização deste estudo, o Município de São Paulo passa a incorporar as atividades da economia criativa como parte da sua estratégia de crescimento e desenvolvimento econômico, geração de renda e promoção de empregos.

Coelho (2019) aponta como esta cidade-espetáculo vai se organizar a partir do planejamento econômico, voltado para a produção e consumo de mercado, atrelados a mercadorias e imagem. Esta interpretação permite novos olhares sobre a relação entre a produção de cultura e o espaço urbano, que dialogam com a perspectiva de atuação da Spcine.

Este contexto está plenamente destacado na forma de atuação da Spcine e seus arranjos na promoção de São Paulo como centro de produção audiovisual. Nas palavras da cineasta e atual diretora-presidente da Spcine, 
Laís Bodanzky, "a cidade é um 'presente' para quem está atrás das câmeras. O Centro está muito conservado. Em um tour que fizemos, fomos vendo que o nosso Centro é ótimo para as filmagens" (PARENTE, 2019, $s / p)$.

A promoção de determinadas áreas das cidades, como os ícones arquitetônicos, seus centros históricos, parques, áreas com reconhecido valor histórico e cultural, etc., cumpre importante papel na construção das imagens das cidades. Como afirma Ferrara (2000), este processo ocorre a partir da criação de determinados redutos, que figuram como cartões postais da cidade, e passam a ser disseminados através de todas as formas de comunicação, construindo um padrão de imagens e estereótipos metafóricos de todas as cidades.

Neste sentido, a produção audiovisual, em especial a obra cinematográfica, é utilizada como forma eficaz de promover as cidades, seja através do turismo ou mostrando que a cidade pode oferecer retornos financeiros aos investimentos, a partir de múltiplas áreas de atuação, como mercado imobiliário, por exemplo. Ao mesmo tempo, a produção audiovisual incorpora o valor construído a partir da imagem das cidades, como Laís Bodanzky complementa "...falamos que São Paulo tem 'plano' com valor de produção. Ou seja, mesmo se não houver muita verba envolvida [no orçamento], a imagem [da cidade] gera um maior valor para a produção" (PARENTE, 2019, s/p). Neste sentido, afirma Coelho (2019, p. 20):

Trata-se, assim, de capitais simbólicos coletivos, apropriados privadamente por aqueles que desenvolvem negócios nessas cidades consideradas globais, ou seja, com capacidade para atrair investidores e turistas de diferentes regiões do mundo, e que competem entre si, necessitando manter e desenvolver as suas singularidades culturais, para obter o máximo de capital simbólico, com base nessa especificidade.

O incentivo à produção audiovisual na cidade de São Paulo, com especial destaque para a produção internacional de grande repercussão midiática global, é incorporado a atuação da Spcine e também inclui esta visão. Conforme destacado em Parente (2019, s/p), "'o plano é entrar mais REU, Sorocaba, SP, v. 45, n. 2, p. 307-330, dez. 2019. 
ainda no radar oficial das grandes produções internacionais', afirma Laís Bodanzky, que espera que a cidade fique parecida com Nova York em termos de filmagens".

A construção das imagens da cidade de São Paulo, aproximando-a de outras grandes cidades globais, a partir do incentivo à produção audiovisual também deve ser objeto de interpretação crítica. Neste contexto, a construção e promoção de imagens, muitas vezes, exalta uma parcela da cidade que guarda pouca relação com seu contexto geral. Ao buscar se aproximar de grandes cidades globais, a desigualdade presente nas metrópoles do mundo subdesenvolvido, como é o caso de São Paulo, praticamente desaparece.

Este processo pode ser interpretado de forma a evidenciar uma construção metafórica de cidade, que não encontra um paralelo equivalente na cidade real, bem como buscar uma conexão entre as tradicionais cidades globais, diminuindo os seus atributos, de fato únicos, para ressaltar aspectos que são comparáveis em todas as grandes cidades mundiais. Como destaca Ferrara (2000, p. 77):

\begin{abstract}
Entre a imagem de cartão-postal global e as contradições e descompassos que estão escondidos há uma curiosa reflexão que deve ser feita porque, naquela duplicidade, o território da visibilidade da cidade se vê simultaneamente reduzido e ampliado: reduzido porque São Paulo se descobre diretamente colonizada pela imagem de outras tantas cidades tão fantásticas quanto ela e infiltrada por uma imagem importada, quando pensava reinar soberana no seu processo de metropolização e gigantismo; ampliada porque, como consequência da constatação anterior, é possível ver outra dimensão da cidade que revela sua moldura local e entender o que ocorre com ela ao padecer da constante necessidade de modernizar-se, a fim de parecer o que não é: enfim, aquela duplicidade impõe encontrar uma São Paulo imersa na dinâmica da sua alteridade global que repele a unidade de uma imagem importada, mas entre em conflito com a imagem que the permitiria identificar-se como diversidade.
\end{abstract}

Assim, destaca-se que a promoção de uma política de fomento ao setor audiovisual na cidade de São Paulo, através das ações e programas desenvolvidos pela Spcine, busca, dentre outros aspectos, associar a cidade de São Paulo às grandes cidades globais, utilizando-se de elementos 
culturais para posicioná-la nesta rede. Este aspecto guarda pouca relação, ou mesmo nenhuma, com o intuito de promover o fomento à cultura, enquanto um processo democratizante de acesso, bem como livre de sua relevância econômica.

O presente trabalho buscou analisar possíveis relações e impactos da política de fomento ao setor audiovisual, desenvolvidas no Brasil nas últimas três décadas, com formas de promoção das cidades em um contexto de competição entre as cidades globais para atração de fluxo de capitais e investimentos, de maneira a garantir crescimento e desenvolvimento econômico local.

Para tal, buscou analisar brevemente as políticas de fomento ao setor audiovisual estruturadas pelo Governo Federal e seus impactos positivos do ponto de vista econômico. Neste sentido, buscou-se, também, interpretar criticamente as análises que consideram unicamente os impactos econômicos como condicionantes de uma política pública bem-sucedida, muitas vezes desconsiderando seus impactos na promoção da cultura e democratização do seu acesso.

A expansão do setor audiovisual, principalmente nos últimos quinze anos, promoveu também novas políticas públicas, em especial no âmbito regional e municipal, como forma de promover desenvolvimento local através dos investimentos realizados pelo setor. Este processo foi discutido através das análises sobre a Empresa de Cinema e Audiovisual de São Paulo (Spcine).

A proposta de lei que fundamentou a criação da Spcine, como discutido na seção 3 deste trabalho, já apresentava um olhar sobre a política de fomento ao setor audiovisual que colocava os impactos econômicos resultantes da intervenção estatal, bem como a visibilidade e promoção midiática da cidade, como pilares fundamentais de sua forma de atuação. 
Assim, a quarta seção buscou avaliar criticamente o processo de fomento à cultura enquanto atributo para promoção das cidades em uma disputa internacional por maior destaque dentre as chamadas cidades globais. Como apresentado, as diversas formas de utilização da cultura como aspecto da formação das imagens das cidades estão colocadas nas propostas de fomento ao setor audiovisual.

Como destacado por Debord (2008), em um contexto que a cultura é alçada a posição central do desenvolvimento, a cidade também passa a representar outro papel na dinâmica capitalista. O autor ainda destaca que o urbanismo acaba por se tornar uma forma de expressão da tomada capitalista do ambiente natural. Neste sentido, as cidades contemporâneas, bem como suas disputas por fluxos de investimentos e valorização do capital através do meio urbano, acabam por transformar o espaço em cenário, o que reflete a importância da promoção do setor audiovisual.

Por fim, este trabalho busca promover uma reflexão sobre as políticas de fomento ao setor audiovisual, tanto em âmbito federal, como local. Festejadas por seus expressivos resultados econômicos, mas ainda pouco avaliadas em seus aspectos culturais fora da dinâmica econômica, sua utilização enquanto forma de promoção das cidades, em um contexto de espetáculo, abre uma sugestão de reflexão sobre as bases do fomento à cultura no Brasil.

\section{Referências}

ASSOCIAÇÃO BRASILEIRA DE PRODUÇÃO DE OBRAS AUDIOVISUAIS - APRO. Mapeamento e impacto econômico do setor audiovisual no Brasil - 2016. APRO/SEBRAE, 2016. Disponível em:

https://bibliotecas.sebrae.com.br/chronus/ARQUIVOS_CHRONUS/bds/bds.nsf/b0 9ddeb1b21ee94db5de582a7f813eb4/\$File/7471.pdf. Acesso em: 15 dez. 2019.

ARANTES, Otília. Uma estratégia fatal: a cultura nas novas gestões urbanas. In: ARANTES, Otília; VAINER, Carlos; MARICATO, Ermínia. A cidade do

pensamento único: desmanchando consensos. Petrópolis: Vozes, 2000. p. 1174.

BRASIL. Decreto No 9.919, de 18 de julho de 2019. Brasília, 2019.

Disponível em: http://www.planalto.gov.br/ccivil_03/_ato2019-

2022/2019/Decreto/D9919.htm. Acesso em: 10 dez. 2019.

REU, Sorocaba, SP, v. 45, n. 2, p. 307-330, dez. 2019. 
BRASIL. Tribunal de Contas da União - TCU. Acórdão 721/2019 de 27 de março de 2019. Brasília. 2019. Disponível em: http://www.in.gov.br/materia//asset_publisher/Kujrw0TZC2Mb/content/id/71925348/do1-2019-04-17-ata-9de-27-de-marco-de-2019-71925031. Acesso em: 15 dez. 2019.

CAIADO, Aurílio Sérgio C. [org.]. Economia criativa na cidade de São Paulo: diagnóstico e potencialidade. São Paulo: FUNDAP, 2011.

CARVALHO, Caio Luiz de. Cidade criativas e a transformação. In: REIS, Ana Carla Fonseca; KAGEYAMA, Peter (orgs). Cidades criativas: perspectivas. São Paulo: Garimpo de Soluções, 2011. p. 20

COELHO, Cláudio Novaes Pinto. As relações entre espaço urbano e cultura: da internacional situacionista à cidade global. Tríade: Comunicação, Cultura e Mídia, Sorocaba, v. 7, p. 11-29, 2019. Disponível em:

http://periodicos.uniso.br/ojs/index.php/triade/article/view/3380. Acesso em: 15 dez. 2019.

D'AGOSTINO, Rosanne. Especialistas e entidades debatem no STF decreto de Bolsonaro sobre Conselho Superior de Cinema. G1. Disponível em:

https://g1.globo.com/poparte/cinema/noticia/2019/11/05/especialistas-eentidades-debatem-no-stf-decreto-de-bolsonaro-sobre-conselho-superior-decinema.ghtml. Acesso em: 4 dez. 2019.

DEBORD, Guy. A sociedade do espetáculo: comentários sobre a sociedade do espetáculo. Rio de Janeiro: Contraponto, 2008.

FERRARA, Lucrecia D'Alessio. Os significados urbanos. São Paulo: EDUSP/FAPESP, 2000.

FERREIRA, João Sette Whitaker. O mito da cidade global: o papel da ideologia na produção do espaço urbano. 2003. 336f. Tese. (Doutorado em Arquitetura e Urbanismo) - Universidade de São Paulo, São Paulo, 2003.

FERREIRA, Claudino. Cultura e regeneração urbana: novas e velhas agendas da política cultural para as cidades. Tomo, Sergipe, n. 16, p. 29-56, jan./jun. 2010. Disponível em: https://seer.ufs.br/index.php/tomo/article/view/518. Acesso em: 15 dez. 2019.

FERREIRA, Fábio; MORAIS, Kátia; JAMBEIRO, Othon. O audiovisual no campo da economia política da comunicação: abordagens, métodos e notas para uma agenda de pesquisa. Extraprensa, São Paulo, v. 10, n. 2, p. 4-23, 2017. Disponível em: http://www.revistas.usp.br/extraprensa/article/view/121975. Acesso em: 15 dez. 2019.

GIOVANNI, Geraldo di. As estruturas elementares das políticas públicas: notas para uma metodologia de análise e avaliação. Caderno de Pesquisa do Núcleo de Estudos de Políticas Públicas, Campinas, n. 82, p. 1-23, 2009. Disponível em: http://www.bibliotecadigital.unicamp.br/document/?down=105472. Acesso em: 15 dez. 2019.

KACHANI, Morris. A possível morte por asfixia da Ancine. O Estado de S. Paulo. Disponível em https://brasil.estadao.com.br/blogs/inconsciente-coletivo/amorte-por-asfixia-da-ancine/. Acesso em: 4 dez. 2019.

MACHADO, Ana Flávia. Economia da Cultura e Economia Criativa: consensos e dissensos. In: LEITÃO, Cláudia; MACHADO, Ana Flávia [Org.]. Por um Brasil criativo: significados, desafios e perspectivas da economia criativa brasileira. 1 
ed. Belo Horizonte: Código, 2016. p. 53-62.

MAIA, Gustavo. Bolsonaro fala em extinguir Ancine 'se não puder ter filtro' ou transformar agência em secretaria. O Globo, Brasil. Disponível em:

https://oglobo.globo.com/cultura/bolsonaro-fala-em-extinguir-ancine-se-naopuder-ter-filtro-ou-transformar-agencia-em-secretaria-23819229. Acesso em: 4 dez. 2019.

MINISTÉRIO DA CULTURA - MINC. Plano da Secretaria de Economia Criativa: políticas, diretrizes e ações 2011-2014. Brasília: MINC, 2011. Disponível em: http://www2.cultura.gov.br/site/wp-content/uploads/2011/09/Plano-daSecretaria-da-Economia-Criativa.pdf. Acesso em: 15 dez. 2019.

MORAIS, Kátia. A Política de Fomento ao Audiovisual no Brasil e o lugar da TV. Eptic On-Line, Sergipe, v. 18, p. 65-85, 2016. Disponível em: https://seer.ufs.br/index.php/eptic/article/view/5216. Acesso em: 15 dez. 2019.

OLIVEIRA, João Maria de; ARAUJO, Bruno Cesar de; SILVA, Leandro Valério. Panorama da economia criativa no Brasil. Rio de Janeiro: IPEA, 2013. Disponível em:

http://repositorio.ipea.gov.br/bitstream/11058/2026/1/TD_1880.pdf. Acesso em: 15 dez. 2019.

PARENTE, Edianez. Com mil filmagens por ano, São Paulo vira meca do cinema na América Latina. UOL, Brasil. Disponível em:

https://noticiasdatv.uol.com.br/noticia/mercado/com-mil-filmagens-por-ano-spvira-meca-do-cinema-na-america-latina-28952. Acesso em: 2 nov. 2019.

PREFEITURA abre Ancine para desenvolver e implementar projetos para cinema. DIÁRIO OFICIAL, São Paulo, Ano 61, n. 246, 31 dez. 2016. Disponível em: http://www.capital.sp.gov.br/noticia/prefeitura-abre-spcine-para-desenvolverfinanciar. Acesso em: 2 nov. 2019.

RIBEIRO, Márcio Rodrigo. A Metrópole nas Telas: a SPCINE e novas oportunidades para o mercado audiovisual paulistano. In: CONGRESSO IBERCOM, 15., Lisboa, São Paulo, 2017. Anais... Lisboa e São Paulo: ECA-USP e FCH-UCP, 2017. p. 4858-4880.

SANTOS, Sérgio Ribeiro de Aguiar. Políticas públicas de cinema: o impacto do fundo setorial do audiovisual na cadeia produtiva do cinema brasileiro. 2017. 356 f. Tese. (Doutorado em Comunicação) - Universidade de Brasília, Brasília, 2017.

SASSEN, Saskia. The global city: New York, London, Tokio. New Jersey: Princeton University, 1988.

SOUSA, Ana Paula. Com somente um diretor, Ancine está à beira do colapso. Disponível em: https://www1.folha.uol.com.br/ilustrada/2019/10/com-somenteum-diretor-ancine-esta-a-beira-do-colapso.shtml. Folha de S. Paulo, São Paulo, 2019. Acesso em: 4 dez. 2019.

TENDÊNCIAS CONSULTORIA INTEGRADA. O impacto econômico do setor audiovisual brasileiro. Rio de Janeiro: Motion Picture Association América Latina, 2016.

UNITED NATIONS CONFERENCE ON TRADE AND DEVELOPMENT - UNCTAD. Creative economy report 2010. Geneva: United Nations Conference on Trade and Development, 2010. Disponível em:

https://unctad.org/en/Docs/ditctab20103_en.pdf. Acesso em: 15 dez. 2019. 